\title{
Clinical Analysis of Laryngeal Tuberculosis: Recent 10 Years' Experience in a Single Institution
}

\author{
Ji-Hoon Kim ${ }^{1}$ (D), Tae Hoon Kong ${ }^{2}$ (D), Hong-Shik Choi ${ }^{3}$ (D) and Hyung Kwon Byeon ${ }^{4}$ \\ 'Department of Otorhinolaryngology, National Health Insurance Service Ilsan Hospital, Goyang, Korea \\ 2Department of Otorhinolaryngology-Head and Neck Surgery, Yonsei University Wonju College of Medicine, Wonju, Korea \\ ${ }^{3}$ Jeil ENT Clinic, Seoul, Korea \\ ${ }^{4}$ Department of Otorhinolaryngology-Head and Neck Surgery, Soonchunhyang University College of Medicine, Soonchunhyang University Seoul \\ Hospital, Seoul, Korea
}

후두 결핵의 임상 양상 분석: 최근 10 년간 단일 기관의 경험

김지훈 ${ }^{1}$, 공태훈 ${ }^{2}$, 최홍식 ${ }^{3}$, 변형권4

국민건강보험 일산병원 이비인후과, ${ }^{1}$ 연세대학교 원주의과대학 이비인후과학교실, ${ }^{2}$ 제일이비인후과, ${ }^{3}$ 순천향대학교 의과대학 순천향서울병원 이비인후과학교실4

Background and Objectives The overall incidence of laryngeal tuberculosis (LT) has generally decreased over the recent years, yet there is still a discrete population of patients newly diagnosed with the disease. This study is aimed to examine the patients with LT over the recent 10 years and to investigate the changes in clinical pattern with respect to the past period. Materials and Method A retrospective review has been performed on 20 patients who have been initially diagnosed with LT between 2005 and 2015.

Results The age of the patients ranged from 25 years to 95 years with an average age of 45.6 years. Seventeen patients (85\%) showed hoarseness, which was the most common clinical symptom. Most affected lesion was the true vocal cord. Laryngoscopic examination showed various clinical manifestations: polypoid 30\%, granulomatous $25 \%$, nonspecific $25 \%$, ulcerative $20 \%$. A variety of methods were used for diagnostic confirmation of LT [acid-fast bacilli (AFB) smear $45 \%$, AFB culture 40\%, polymerase chain reaction 30\%, surgical pathology $45 \%$ ]. Coexisting pulmonary tuberculosis (PT) was detected in 10 patients (50\%). Relative to the patients with inactive PT or normal lung status, those with active PT showed higher incidence of laryngeal lesions located in areas other than true vocal cord ( $p=0.050$ ).

Conclusion Based on the analytic results from this study, laryngologists should recognize the changes in the recent clinical patterns of LT and always be ready for clinical suspicion of this disease on such atypical laryngeal findings which can often mimic laryngeal malignancies to provide the pertinent treatment.

Keywords Laryngeal tuberculosis; Laryngeal cancer; Pulmonary tuberculosis.

\section{서 론}

대한민국의 결핵 유병률은 10 만 명당 77 명, 사망률은 10 만 명당 5.2 명으로 여전히 경 제협력개발기구(organization for economic cooperation and development) 국가 중에

\author{
Received October 12, 2020 \\ Revised November 4, 2020 \\ Accepted November 15, 2020

\section{Corresponding Author} \\ Hyung Kwon Byeon, MD, PhD \\ Department of Otorhinolaryngology- \\ Head and Neck Surgery, \\ Soonchunhyang University \\ College of Medicine, \\ Soonchunhyang University Seoul Hospital, \\ 59 Daesagwan-ro, Yongsan-gu, \\ Seoul 04401, Korea \\ Tel +82-2-709-9360 \\ Fax+82-2-795-3687 \\ E-mail ewellcastle@gmail.com
}

\section{ORCID iDs}

Ji-Hoon Kim (D)

https://orcid.org/0000-0003-2363-5060

Tae Hoon Kong (D)

https://orcid.org/0000-0002-5612-5705

Hong-Shik Choi (D)

https://orcid.org/0000-0002-9612-1303

Hyung Kwon Byeon (D)

https://orcid.org/0000-0003-3709-2028

\author{
This is an Open Access article distributed \\ under the terms of the Creative \\ Commons Attribution Non-Commercial \\ License (https://creativecommons.org/ \\ licenses/by-nc/4.0) which permits \\ unrestricted non-commercial use, \\ distribution, and reproduction in any \\ medium, provided the original work is \\ properly cited.
}


가장 높은 수치를 나타내고 있다. 전 세계적으로는 약 7백만 명의 결핵 환자가 발생하고, 1.5 백만 명가량이 결핵으로 사망 하는 것으로 보고되고 있다. ${ }^{2)}$ 결핵은 Mycobacterium tuberculosis가 원인이며, 주로 폐에서 발생하지만 드물게 폐외 장 기에서도 발생한다. 이 중 후두 결핵(laryngeal tuberculosis) 은 폐외 결핵의 $2 \%$ 미만을 차지하지만, 후두에서 가장 흔하 게 발생하는 육아종성(granulomatous) 질환으로 음성 변화 나 연하 곤란을 유발한다. ${ }^{3,4)}$ 하지만 모든 폐 결핵 환자에서 후 두 내시경 검사를 시행하는 것은 아니며, 후두 병변에 대한 조직 검사를 통해서만 후두 결핵을 확진할 수 있기 때문에 실제 유병률은 이보다 더 높을 것으로 예상된다. 후두 결핵은 흔한 질환이 아니기 때문에 임상 경험이 없는 경우 오진의 가 능성이 있고, 그로 인해 적절한 치료 시기를 놓칠 수 있다. 후 두 결핵에 대한 기존 문헌의 보고는 대부분 1970 90년대에 발표되었으며, ${ }^{5)}$ 국내에서도 2008년 이후에는 관련 문헌이 보 고된 바가 없어, 이에 저자들은 최근 10 년간 단일 기관에서 경험한 후두 결핵 환자 20 명의 증례 분석을 통해 상기 질환 의 임상 특성에 변화가 있는지 확인하고자 하였다.

\section{대상 및 방법}

본 연구는 2005년 1월 2015년 12월까지 강남세브란스병원 에 내원하여 후두 결핵을 진단받은 20명의 환자들을 대상으 로 의무 기록과 후두 내시경 검사 기록을 후향적으로 분석하 였다. 후두 결핵의 진단은 1) 조직병리학적으로 후두 결핵을 확진받은 경우, 2) 후두 내시경 소견상 결핵을 의심할 만한 특 징적인 후두 병변이 관찰되고, 흥부방사선촬영에서 폐결핵이 보이거나, 항산균 도말 검사와 배양 검사, 혹은 결핵균 핵산 증폭 검사(polymerase chain reaction)에서 양성이며 항결 핵제 복용 후 병변이 호전된 경우로 한정하였다. 면담을 통해 환자의 주 증상과 전신 증상 동반 여부를 확인하였으며, 후두 내시경 검사를 시행하여 후두 병변의 위치를 확인하고, 기존 보고들을 기반으로 하여 내시경 소견에 따라 궤양형(ulcerative), 육아종형(granulomatous), 폴립형(polypoid), 비특이 형(nonspecific)의 4가지 아형으로 형태학적인 유형을 분류 하였다(Fig. 1). ${ }^{6}$ 흥부방사선촬영, 항산균 도말 검사, 배양 검 사, 결핵균 핵산 증폭 검사 결과를 확인하여 결핵의 활동성
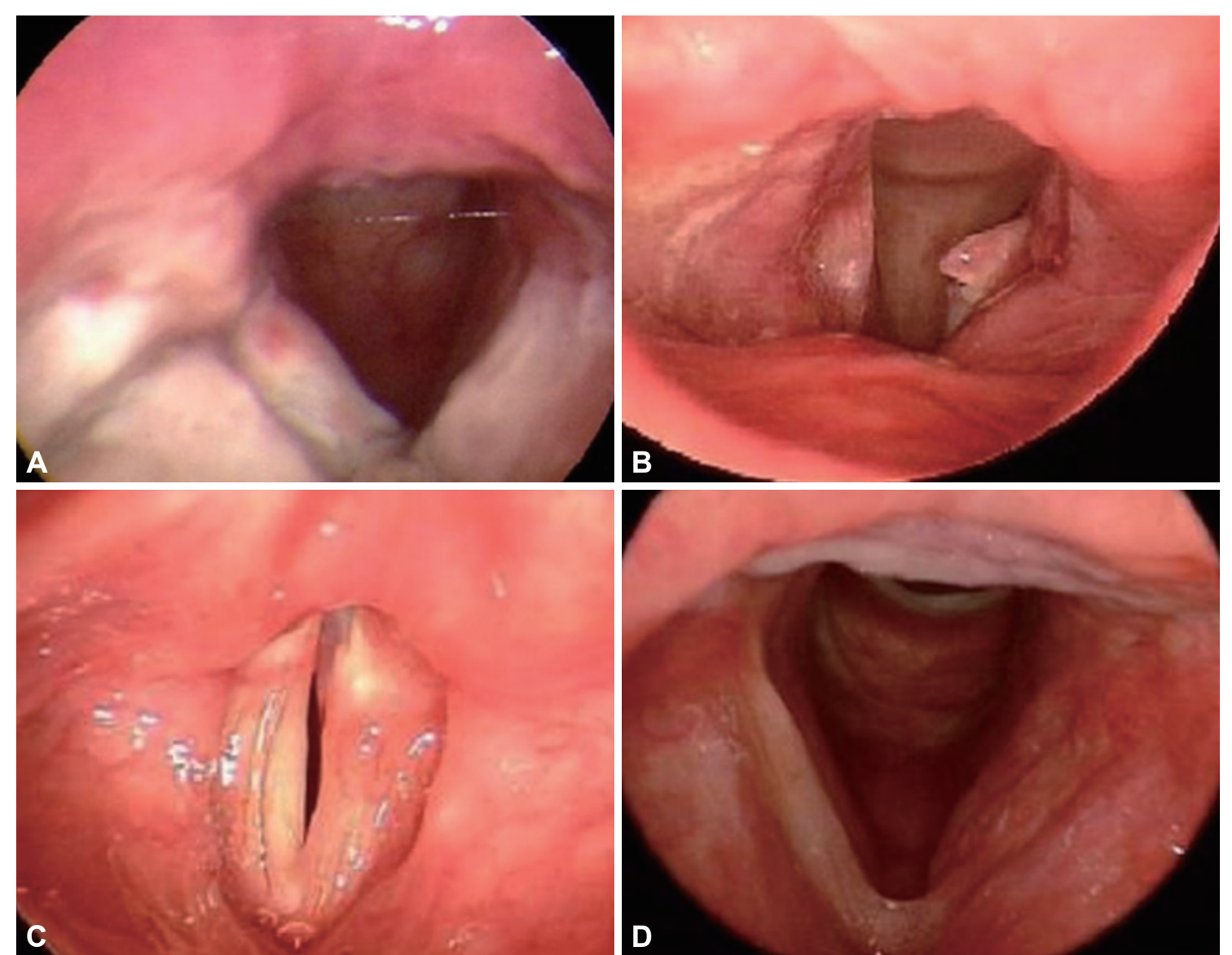

Fig. 1. Videolaryngoscopic findings of 4 types of laryngeal tuberculosis. A: Ulcerative type. B: Granulomatous type. C: Polypoid type. D: Nonspecific inflammatory type. 
여부를 판단하였다. 흥부방사선촬영에서 폐 상엽에 침윤(infiltration), 경화(consolidation), 공동(cavity) 등의 소견이 관 찰되는 경우에는 활동성 폐 결핵으로 진단하였으며, 영상의 학과 전문의의 판독을 통해 병변 유무를 확인하였다. 항결핵 제 치료가 종료된 후에는 후두 내시경 검사 및 객담 검사를 통해 호전 여부를 임상적으로 판단하였다.

범주형의 변수 자료들은 카이 제곱 검정(chi-square test) 및 Fisher의 정확 검정(Fisher's exact test)을 이용하여 분석 하였다. 통계 분석은 Statistical Packages for Social Science (SPSS 22.0 for Windows, IBM Corp., Armonk, NY, USA) 를 이용하였고, $\mathrm{p}$ 값이 0.05 미만이면 통계적으로 유의한 것 으로 간주하였다.

\section{결 과}

총 20명 환자의 평균 연령은 45.6세(25 95세)였다. 그 중 남성은 8 명이며 평균 연령은 53.3 세이고, 여성은 12 명으로 평 균 연령은 40.5 세였다. 전체 환자 중 애성을 호소하는 경우는 17 명(85\%)으로 가장 많았으며, 기침은 6명(30\%), 호흡곤란을 호소하는 환자도 3 명 $(15 \%)$ 이 있었다. 하지만 결핵의 전신 증상 인 야간 발한, 체중 감소를 호소한 경우는 각각 1명씩이었다.

후두 결핵의 형태학적 특징을 기반으로 궤양형, 육아종형, 폴립형, 비특이형의 4 가지 아형으로 분류하였다. 각각의 아형 들이 단독으로 존재하는 경우는 11 명이었고, 여러 아형이 복 합적으로 존재하는 경우는 9 명이었다. 아형이 단독으로 존재 하는 경우 폴립형은 5명, 비특이형은 3명, 육아종형은 2명, 궤 양형은 1 명이었으며, 여러 아형이 복합적으로 존재하는 경우 가장 우세한 아형을 기준으로 분류하였을 때 육아종형은 3명, 궤양형은 3 명, 비특이형은 2 명, 폴립형은 1 명이었다. 전체 환자 로 보았을 때는 폴립형을 보이는 경우가 6명으로 가장 많았 으며, 육아종형은 5명, 비특이형은 5명, 궤양형은 4명이었다.

후두 병변이 관찰되는 부위를 기준으로 구분하였을 때 단 일 부위만 침범한 경우는 11 명, 여러 부위를 침범한 경우는 9명이었다. 단일 부위를 침범한 경우 11 명 모두 진성대(true vocal cord)에 국한되어 병변이 관찰되었고, 여러 부위를 침 범한 경우에는 진성대를 침범한 경우가 7명, 가성대(false vocal cord)를 침범한 경우가 5명, 후두개(epiglottis), 피열 연골 (arytenoid cartilage), 후교련 부위(posterior commissure)를 침범한 경우가 각각 2 명씩이었다.

9명의 환자에서 전신마취하에 조직 검사를 시행하여 결핵 을 확진하였고, 그 중 5 명은 후두암이 의심되어 수술을 진행 하였으나 모두 결핵으로 확진된 경우였다. 나머지 11 명의 경 우 객담 검사 결과를 기반으로 후두 내시경 검사를 통해 임
상적으로 결핵으로 판단하여 조직 검사 없이 치료를 진행하 였다. 항산균 도말 검사에서 양성으로 보고된 경우는 9명, 배 양 검사에서 양성으로 보고된 경우는 8명, 핵산 증폭 검사에 서 양성으로 보고된 경우는 6 명이었다.

흥부방사선촬영 결과에서 활동성 폐 결핵이 확인된 경우 는 10 명, 비활동성인 경우는 4 명, 정상 소견은 6 명이었다. 흥 부방사선촬영은 정상이었으나 객담 검사에서 양성으로 보고 된 경우는 5 명으로 확인되었다. 흥부방사선촬영, 항산균 도말 및 배양 검사, 핵산 증폭 검사 모두에서 음성이었으나 후두 병변 조직 검사에서 결핵으로 확진된 환자는 1 명이었다.

흥부방사선촬영 결과를 바탕으로 폐 결핵 활동성 여부에 따른 후두 병변의 다발성 여부 및 병변의 유형의 차이는 통계 학적으로 유의하지 않았다. 폐 결핵의 활동성 여부에 따라 후두에 침범하는 병변의 위치는 통계학적으로 유의하지 않 았으나, 이를 병변의 위치가 진성대에 국한된 경우와 그렇지 않은 경우로 나누어 분석하였을 때, 진성대 이외의 병변은 활 동성 폐 결핵 환자에서 발생하는 빈도가 유의하게 높은 것으 로 확인되었다 $(\mathrm{p}=0.050)$ (Table 1).

후두 결핵의 치료는 항결핵제(isoniazide, rifampicin, ethambutol, pyrazinamide) 복합 요법을 사용하였다. 흥부방사

Table 1. Comparison of clinical characteristics according to lung status

\begin{tabular}{|c|c|c|c|c|c|}
\hline & & hest X-ra & & Trtal & n wolu \\
\hline & Active & In-active & Normal & 10tal & p value \\
\hline Involvement pattern & & & & & 1.000 \\
\hline Single & 6 & 2 & 4 & 11 & \\
\hline Multiple & 4 & 2 & 2 & 9 & \\
\hline Type & & & & & 0.954 \\
\hline Polypoid & 3 & 1 & 2 & 6 & \\
\hline Granulomatous & 2 & 2 & 1 & 5 & \\
\hline Ulcerative & 3 & 0 & 1 & 4 & \\
\hline Non-specific & 2 & 1 & 2 & 5 & \\
\hline Location 1 & & & & & 0.788 \\
\hline True vocal cord & 8 & 4 & 6 & 18 & \\
\hline False vocal cord & 4 & 0 & 1 & 5 & \\
\hline Epiglottis & 2 & 0 & 0 & 2 & \\
\hline Arytenoid & 1 & 0 & 1 & 2 & \\
\hline $\begin{array}{l}\text { Posterior } \\
\text { commissure }\end{array}$ & 2 & 0 & 0 & 2 & \\
\hline Location 2 & & & & & 0.050 \\
\hline True vocal cord & 8 & 4 & 6 & & \\
\hline Others* & 9 & 0 & 2 & & \\
\hline
\end{tabular}

*Others: false vocal cord, epiglottis, arytenoid, posterior commissure 
선촬영 소견 정상, 객담 검사 음성, 후두 내시경 검사상 병변 의 호전을 확인하여 완치 판정을 하였으며, 치료를 시작한 지 4 15개월 내에 모든 환자에서 완치가 되었다.

\section{고 찰}

후두 결핵은 전체 결핵 중에서는 $1 \%$ 미만으로 드문 질환 으로, 폐 결핵에 동반되어 발생하는 경우가 많다.) 후두 결핵 의 병리 기전은 1) 항산균이 직접 후두에 침범하여 발생하는 경우, 2) 폐 결핵이 진행되어 기관 전이성 감염(bronchogenic spread)을 일으키는 경우의 두 가지로 크게 나뉘어진다. 두 번 째 경우는 폐 기관지에서 발생하는 기침이나 가래에 포함된 항산균이 후두 주변을 오염시키면서 감염되는 것이다. ${ }^{8.9)}$

Lim 등6)은 1994 2004년 10월까지 본 연구와 동일한 기관 에서 발생한 후두 결핵 환자들을 후향적으로 분석하여 보고 한 바 있다. 본 연구의 경우 이후 10년 동안 발생한 후두 결핵 환자들을 분석하여 임상 소견의 변화 양상 확인해보고자 하 였다. $\operatorname{Lim}$ 등의의 보고에 따르면 당시 후두 결핵 환자의 발생 연령대는 40 50대가 많았으며, 남녀 비는 1.9:1이었다. 본 연 구에서는 환자들의 평균 연령은 45.6세로 비슷한 수준이나, 남녀 비는 1:1.5로 여성에서 더 많이 발생하였다. 후두 결핵은 젊은 남자에서 많이 발병하는 것으로 알려져 있었으나, 최근 에는 점차 발병 연령이 높아지고 있으며, 여성 발병도 증가하 고 있다. ${ }^{5)}$ 기존 연구들은 남녀 비가 3 3.6:1 정도로 남성에서 많이 발생하는 것으로 알려져 있었는데, ${ }^{10)}$ 이전의 연구들과 달리 최근에는 여성의 발생 빈도가 높아지고 있는 것을 확인 할 수 있었지만 여전히 성비에 대해서는 다양한 연구 결과가 존재한다.

폐 결핵과 달리 후두 결핵은 전신적인 증상을 동반하기보 다는 애성을 유발하는 경우가 많다. 항산균은 주로 성대의 상 피하 공간(subepithelial space)에 삼출(exudation)을 발생시 키고, 원형 세포(round cell)의 침윤(infiltration)을 유도하여 고유층(lamina propria)의 섬유화를 일으키는 것으로 알려져 있다.11) 진성대는 후두 결핵이 가장 호발하는 부위로서, 진성 대에 병변이 발생하면 발성 시 성대의 진동을 방해하기 때문 에 애성을 유발하게 된다. ${ }^{12,13)}$ 대부분의 환자에서 결핵 진단 당시 1 6개월간의 애성을 호소하였다는 보고가 있다. ${ }^{14)}$ 본 연구에서도 $85 \%$ 의 환자가 애성을 호소하였으며, 전신 증상을 호소하는 환자는 2 명뿐이었다. 이는 폐 결핵에서 전신 증상이 주 증상으로 발현되는 것과는 가장 차이가 있는 부분이다.

Reis 등15)은 36명의 후두 결핵 환자 중에 후두개에서 병변 이 확인된 경우가 $58.3 \%$ 로 보고하였는데, 폐 결핵이 동반된 경우에 후두개에서 결핵 병변이 나타나는 경우가 많았다. 이
는 기도에서 발생한 분비물들이 후두 계곡(vallecula)에 저류 하면서 지속적인 후두 내 감염을 유발하기 때문일 것으로 예 상하였는데, 이런 경우 단일 병변보다는 후두 내 여러 부위에 병변이 발생할 확률이 높다. 본 연구에서는 흥부방사선 소견 이 정상이거나 비활동성 폐 결핵이 동반된 환자군에서는 병변 이 성대 내에만 국한된 경우로 확인되었던 반면, 활동성 폐결 핵이 동반된 환자군에서는 진성대뿐 아니라 가성대와 후두개 등의 다양한 부위에 침범되는 경우가 많았다. 이는 Reis 등 15$)$ 의 결과에는 못 미치지만 다소 유사한 경향을 보이고 있고 폐 결핵의 기관 전이성 감염을 시사하는 결과라고 할 수 있겠다.

후두 결핵은 후두 내시경 검사를 통해 다양한 유형으로 구분할 수 있다. 항생제가 사용되기 전에는 육아종성 유형이 $10 \%$ 미만으로 적었으나, 항생제가 사용된 이후에는 육아종 성 유형이 후두 결핵의 $60 \%$ 이상을 차지하였다. ${ }^{16)}$ 본 연구에 서는 육아종성 유형이 $25 \%$ 를 차지하였으며, 그 외의 유형들 이 골고루 분포되어 있었다. 후두암이 의심되어 조직 검사를 시행한 경우도 5 명 $(25 \%)$ 이나 되어, 임상적인 소견만으로 판단 하기가 어려울 정도로 다양한 유형의 병변이 발생하는 것을 알 수 있었다.

후두암은 후두 결핵과 감별해야 할 질환 중 가장 주된 질 환이다. Levenson 등 17)은 후두 결핵으로 진단된 환자의 $50 \%$ 이상에서 악성이 의심되었다고 보고하였다. 본 연구에서는 $25 \%$ 의 환자가 악성의 의심되어 조직 검사를 시행하였으나 모 두 결핵으로 진단되었다. 병변의 형태만으로는 감별하기 어 려운 경우가 많기 때문에 이비인후과 의사들은 정확한 진단 을 위해 주의를 기울여야 하며, 후두 결핵과 후두암이 공존 하는 증례 보고도 있기 때문에 임상적으로 감별이 어려울 경 우 반드시 조직 검사를 통한 확진이 필요하다. ${ }^{18)}$ 초기 후두 결핵은 감염성 후두염으로 오인될 가능성이 있으며, 매독, 방 선균증(actinomycosis), 베게너 육아종증(Wegener'sgranulomatosis)과도 감별이 필요하다.

일반적으로 폐 결핵 환자에서 후두 내시경 검사를 시행하 지는 않는다. 그러나 폐 결핵이 의심되어 검사를 받는 환자 중 에 음성 변화를 호소하는 환자가 있을 경우, 후두 내시경 검 사를 통해 후두 결핵 동반 여부를 확인하는 것이 필요하며, 악성 종양과 감별이 어려울 경우 조직 검사를 통한 확진이 반드시 필요할 것으로 생각된다. 이 때, 의료진은 환자의 가 래에 노출될 수 있으므로 반드시 N-95 마스크를 착용한 후 후두 내시경 검사를 시행하는 것이 필요하다.

\section{결 론}

본 연구의 전체 환자 수가 작기 때문에 연구 결과를 일반화 
하기에는 무리가 있지만, 기존에 알려진 후두 결핵의 특성들 이 점차 둔화되고 있는 양상을 보이며 비전형적인 소견들을 나타내는 것을 확인하였다. 결핵의 빈도가 줄어들고 있지만 후두 병변의 감별 진단에 결핵을 포함시켜, 진단이 늦어지거 나 치료가 지연되지 않도록 주의하여야 하겠다.

중심 단어: 후두 결핵, 후두암, 폐결핵.

\section{Acknowledgments}

None.

\section{Conflicts of Interest}

The authors have no financial conflicts of interest.

\section{Authors' Contribution}

Conceptualization: Ji-Hoon Kim, Hong-Shik Choi, Hyung Kwon Byeon. Data curation: Ji-Hoon Kim, Tae Hoon Kong, Hong-Shik Choi. Methodology: Ji-Hoon Kim, Tae Hoon Kong, Hyung Kwon Byeon. Writing — original draft : Ji-Hoon Kim. Writing-review \& editing : Tae Hoon Kong, Hyung Kwon Byeon. Approval of final manuscript: all authors.

\section{REFERENCES}

1. Cho KS. Tuberculosis control in the Republic of Korea. Epidemiol Health 2018;40:e2018036.

2. Harding E. WHO global progress report on tuberculosis elimination. Lancet Respir Med 2020;8(1):19.

3. Rizzo PB, Da Mosto MC, Clari M, Scotton PG, Vaglia A, Marchiori C. Laryngeal tuberculosis: an often forgotten diagnosis. Int J Infect Dis 2003;7(2):129-31.

4. Nalini B, Vinayak S. Tuberculosis in ear, nose, and throat practice: its presentation and diagnosis. Am J Otolaryngol 2006;27(1):39-45.
5. Benwill JL, Sarria JC. Laryngeal tuberculosis in the United States of America: a forgotten disease. Scand J Infect Dis 2014;46(4):241-9.

6. Lim JY, Kim KM, Choi EC, Kim YH, Kim HS, Choi HS. Current clinical propensity of laryngeal tuberculosis: review of 60 cases. Eur Arch Otorhinolaryngol 2006;263(9):838-42.

7. Chen H, Thornley P. Laryngeal tuberculosis: a case of a non-healing laryngeal lesion. Australas Med J 2012;5(3):175-7.

8. Singh K, Kaur G, Parmar TL. Pseudo tumoral laryngeal tuberculosis. Indian Pediatr 2003;40(1):49-52.

9. Unal M, Vayisoglu Y, Guner N, Karabacak T. Tuberculosis of the aryepiglottic fold and sinus pyriformis: a rare entity. Mt Sinai J Med 2006; 73(5):806-9.

10. Bailey CM, Windle-Taylor PC. Tuberculous laryngitis: a series of 37 patients. Laryngoscope 1981;91(1):93-100.

11. Ozüdogru E, Cakli H, Altuntas EE, Gürbüz MK. Effects of laryngeal tuberculosis on vocal fold functions: case report. Acta Otorhinolaryngol Ital 2005;25(6):374-7.

12. Nishiike S, Irifune M, Doi K, Sawada T, Kubo T. Laryngeal tuberculosis: a report of 15 cases. Ann Otol Rhinol Laryngol 2002;111(10): 916-8.

13. Wang CC, Lin CC, Wang CP, Liu SA, Jiang RS. Laryngeal tuberculosis: a review of 26 cases. Otolaryngol Head Neck Surg 2007;137(4): 582-8.

14. Porras Alonso E, Martín Mateos A, Perez-Requena J, Avalos Serrano E. Laryngeal tuberculosis. Rev Laryngol Otol Rhinol (Bord) 2002; 123(1):47-8

15. Reis JG, Reis CS, da Costa DC, Lucena MM, Schubach Ade O, Oliveira Rde V, et al. Factors associated with clinical and topographical features of laryngeal tuberculosis. PLoS One 2016;11(4):e0153450.

16. Kurokawa M, Nibu K, Ichimura K, Nishino H. Laryngeal tuberculosis: a report of 17 cases. Auris Nasus Larynx 2015;42(4):305-10.

17. Levenson MJ, Ingerman M, Grimes C, Robbett WF. Laryngeal tuberculosis: review of twenty cases. Laryngoscope 1984;94(8):1094-7.

18. Lin CJ, Kang BH, Wang HW. Laryngeal tuberculosis masquerading as carcinoma. Eur Arch Otorhinolaryngol 2002;259(10):521-3. 